\title{
Formation of digital competencies of future life safety teachers
}

\author{
Viktoria Safonova $^{1 *}$, Ekaterina Lutovina $^{1}$, and Irina Korneva ${ }^{1}$ \\ ${ }^{1}$ Orenburg State Pedagogical University, 460014, Orenburg, Russian Federation
}

\begin{abstract}
The article discusses the actual problems of the formation of future teachers' digital competencies, which are an important aspect of professional success. The positive aspects of education digitalization are shown. The task of improving the process of developing digital competencies of future teachers studying in the profiles of Life Safety and Physical Education is being solved. The formation of future teachers' digital competencies of the life safety basics is considered from the standpoint of a metasubject approach. It is shown that the formation of digital competencies of future life safety teachers is a process of purposeful pedagogical influence on a student in order to develop a set of skills, abilities and knowledge that allows using digital technologies effectively to solve professional problems at all levels of education. The conditions for the formation of digital competencies are determined. The formation of the components of digital competence among practicing teachers of life safety is considered. It is shown that the formation of digital competencies of future life safety teachers is possible implementing specialized disciplines, educational and industrial practices that include the organization of pedagogical activities in a digital environment from the standpoint of health preservation, creating a comfortable educational environment.
\end{abstract}

\section{Introduction}

At the present stage of education development, we observe changes in the requirements for a subject teacher. Today's education system worker must have a good subject theoretical background, have experience in implementing optimal and effective educational technologies, be not only a translator of knowledge, but also a mentor of students, taking into account their individual characteristics, life and professional needs and educational tasks $[1,2]$.

Nowadays the education sector, as never before, is turned to the implementation of new national projects, programs, standards and recommendations. In Russia, the foundation of the regulatory framework defining the requirements for the education of future teachers in the digitalization paradigm is left by the "Strategy for the Information Society Development in the Russian Federation for 2017-2030", the program "Digital Economy of the Russian Federation", federal state educational standards. In the federal state educational standards of

\footnotetext{
* Corresponding author: safonova.viktoria@bk.ru
} 
higher education, which regulate the training of future secondary schools teachers, professional competencies are presented, among which digital competencies are of particular importance. Universal and general professional competences listed in federal state educational standards are mandatory for students of higher educational institutions, the digital content of which is universal and meta-subject in nature, and are necessary for the student's successful activity in the digital educational space of a higher educational institution.

The UNESCO recommendations "Structure of ICT Competencies for Teachers" emphasize the relevance of the digital competencies formation, pointing out the need to effectively solve the problems of overcoming the "digital divide", integrating information and communication technologies into the educational process at all levels of education, transforming teaching methods and methodological systems for the formation of students' digital competencies. Therefore, the relevance of the modern stage of education will be inextricably linked with the improvement of the methodological system for the digital competencies development among students of the corresponding higher educational institution. At the same time, students will be interested in "digital transformation", in the digital technologies development, in the emergence and approval of "digital pedagogy" [3].

Digital education carries many positive aspects associated with technical innovations, updating and changing the teaching and educational process, and the use of digital technology. This forces us to improve and develop digital competencies in the educational process of an educational organization in any place of its territorial location. The information and educational environment with the use of information and communication technologies deserves special attention, since it contributes to the formation of those optimal conditions in which it is possible for teachers to develop, improve their professional growth and their professional qualities [4].

One of the tasks of digital education is determined by the construction of an educational process that contributes to the efficiency and safety of education in the context of the use of information and communication technologies [5].

Thus, the pedagogical community today is faced with the task of finding effective organizational and pedagogical conditions in the field of the digital competencies formation of future life safety teachers, capable of creating such an educational environment that will allow young students to develop emotionally, intellectually, socially.

\section{Methods}

The problem of developing digital competencies of a future teacher of the life safety basics determines the effectiveness of professional training and professional success of a novice teacher. Scientific research was carried out on the basis of the Federal Budgetary Educational Institution of Higher Education "Orenburg State Pedagogical University" from 2018 to 2020. During the declared period, a theoretical analysis of the regulatory framework, scientific sources, methodological and other resources was carried out. The pedagogical experiment was attended by teachers, organizers of the life safety basics, undergoing professional retraining (48 people), students studying in the profile: life safety and physical education (52 people). In the course of the described study, the concept of "digital competencies formation of a life safety teacher" was defined, targets and expected results of national projects, national programs, educational standards, recommendations were analyzed in order to determine the current directions for improving the digital competencies of future life safety teachers. A thorough analysis of modern research on digital transformation in the educational process was carried out. The conceptual provisions of modern national scientists were generalized, the issues of improving the methodological support were raised; generalized the pedagogical experience of the study 
regarding the improvement of digital competencies among pedagogical university students, studying in the life safety specialty. The methodological basis was the scientific works of I.A. Winter, E.F. Zeer, G.K. Selevko, A.V. Khutorsky and others on the competence-based approach in education. It is generally accepted that the competencebased approach is associated with the main vectors of education, namely, with learning, self-determination, self-actualization, socialization and the development of individuality in education. To achieve these goals, concepts such as "competence" and "competency" were introduced [6]. Methods of mathematical statistics were used to confirm the reliability of the research results.

\section{Results}

The problem of developing digital competencies in a future life safety teacher is due to the following contradictions:

- between the objective need to solve problems to ensure the accelerated introduction of digital technologies in the economy and the social sphere, training for the digital economy and the insufficient level of development of scientific and methodological support for the digital competencies formation among graduate students of noninformation specialties, in particular students of pedagogical educational institutions of higher education. The revealed contradiction determines the research problem - what organizational, pedagogical and pedagogical conditions contribute to the digital competencies development of future teachers of the life safety basics?

The research object is the educational process in the organization of higher pedagogical education. The purpose of the research is to improve the process of developing digital competencies of future life safety teachers who study in the field of life safety and physical education. The stated goal determined the following research objectives: to define the essence of the concept of "formation of digital competencies of future life safety teachers"; to identify the level of digital competence formation of practicing life safety teachers; to determine the conditions for the digital competence development of future life safety teachers as one of the factors that increase the effectiveness of students' professional training.

Modern information technologies are a prerequisite for improving existing approaches to the educational process and existing teaching methods. In this case, a special role is assigned to information technologies, since their use visually increases the interest of students in learning, makes them to save time, and due to its interactivity and visibility, it forms in them a better understanding and assimilation of the lesson presented by the teacher. Game motivation is characterized by the use of a special methodological technique designed to assist in the management of the participants' activities [7].

A digital school is rightfully considered an open socio-cultural educational environment, a kind of ecosystem where the learning process is carried out by analyzing schoolchildren's needs and demands, the characteristics of their interaction, both among themselves and with other representatives-participants of this educational environment [1].

The digital school provides a specific goal - to ensure effective socialization of a person in a high-tech social ecosystem of society with the mastery and reproduction of its values, such as: norms and rules of behavior, knowledge, skills and competencies in a real living environment, contributing to the formation of a person's identity with its continuous and comprehensive development [8].

Modern researches on digital education emphasizes the importance of the formation of digital competencies in students of educational institutions. 
"Formation" from the point of view of pedagogy is "a process of purposeful pedagogical influence on a student in order to develop certain personality qualities in him" [9].

The system of digital competencies for teachers identifies six areas of digital competencies with an emphasis on the use of digital technologies in order to improve the quality of education at all levels, starting with preschool education: using digital technologies to solve professional problems; the skill of using digital tools for teaching; the skill of information searching for the creation and sharing of digital educational resources; the skill of using digital tools to increase the educational students' potential; abilities and skills to determine the effectiveness of learning outcomes; pedagogical support of educational activities of students in the digital environment [10].

The universality and meta-subjectness of the digital competence of students of a higher educational institution is characterized by work with information,

The digital competence of students of an educational organization of a higher educational institution is an educational universal and meta-subject competence that includes in its content all types of work with information as a source of new knowledge. The formation of digital competence determines the nature of activities in a virtual environment. It promotes self-enrichment with new knowledge, thanks to digital technologies, does not contribute to the development of Internet addiction in the digital environment; reveals new facets for students of a higher educational institution associated with their self-realization and self-improvement [11-13].

From the standpoint of the metasubject approach, the teacher's digital competence is a set of skills, abilities and knowledge that allow him to effectively use digital technologies to solve professional problems at all levels of education, including the search for the creation, use of digital educational resources, the use of digital tools in teaching and learning, in assessment the effectiveness of learning outcomes, the development of students' educational potential and their digital competence [14].

It should be noted that some researchers believe that high digital competence of teachers should not always be compared with a positive attitude towards media in secondary schools. For example, European colleagues, in particular, German teachers, are ready to work with the media three times less than their Russian counterparts. There is an information that students of many pedagogical specialties are critical of teaching computer technologies with the involvement of the Internet. For example, A. Breiter and others find some ambiguity in the attitude of teachers to this situation [15]. On the one hand, they are positive about the active use of media in the professional field, and rather skeptical about the use of media by schoolchildren, explaining this by the existing risks. At the same time, media competence should be limited to certain issues in order to prevent possible threats to the information environment for schoolchildren [16].

Educational risks have a multivariate focus and define a set with elements corresponding to various types of security [17].

In particular, to ensure the social security of students in educational organizations, it is necessary to create an information-safe environment. The understanding of safety in the pedagogical aspect is aimed at solving the problem of ensuring safe conditions for the living and future generations, which makes it necessary to design a safe educational environment and prepare a future teacher for the life safety basics in this direction [18].

A feature of the formation of digital competencies in future life safety teachers is the knowledge of the skills and abilities of preparing secondary school students for safe information and environmental activities.

The success of this task will depend directly on the organizational, methodological and pedagogical approaches in education. In order to reduce the negative informational 
risks, it is necessary that teachers take into account informational risks in terms of social and psychological security [19].

Such work of teachers will be a kind of system of socio-pedagogical and psychological conditions that contribute to the development of the personal sides of students on the basis of building a safe information and educational environment of the individual. This work will contribute to the formation of students' personal characteristics. They will meet all the needs of the modern information society with a built individual educational trajectory with sustainable motivation to study information security issues. In this case, the methods of psychological and pedagogical support for preparing schoolchildren for safe informational and environmental activities are of great importance [20].

The essence of digital competence is considered by us in the following components: cognitive, informational-communicative, operational-activity and emotional-value.

The characteristic of the cognitive component of digital competence includes knowledge: about sources of information and methods of information processing: search, storage, systematization, classification, transportation; about signs of negative and destructive information; about the Internet ethics, about the rules of safety when working on the Internet, information security.

The content of the informational-communicative component is characterized by skills and abilities to create new information, effectively use information sources, critically evaluate, select, classify and systematize the information received, as well as information sources; use software to process information; to be able to organize communication using digital technologies, to reflect on the basis of the received information for effective solving of professional problems.

The operational-activity component is the ability to solve professional problems using digital devices, tools, technologies for the design of the educational process.

The content of the motivational-value component is characterized by understanding and acceptance of ethical standards for working with information, the presence of motivation for the use of digital technologies in order to increase the efficiency of the educational process, the formation of skills and abilities to resist the negative impact of the virtual environment, recognize destructive information, and apply adequate methods of protection against destructive information.

We conducted a sociological survey among teachers at school practicing the subject "Basics of life safety" in order to study the formation of their digital competencies. We have developed a competency questionnaire that allows us to identify the level of formation of the digital competence components among teachers teaching the discipline "Basics of life safety" at school. Analysis of the diagnostic results showed that $77 \%$ of respondents have a high level of cognitive component formation of digital competence. Teachers know about sources of information, about methods of searching, storage, processing and transmitting information, understand the possible negative impact of destructive information on the processes of mental development of minors, about the risks of social development of the student's personality, about ethical standards of behavior in the virtual space, about safety rules when working in the Internet, about digital devices and resources in terms of their use in the educational process. The formation of the information component at a high level was diagnosed by $63 \%$ of the respondents. In general, teachers have skills related to information processing, namely, to create new information, find sources of information, critically evaluate, select, classify and systematize the received information. When assessing the operational-activity component, $88 \%$ of teachers answered that they prefer to use a stationary computer to search and process information, and only $8 \%$ use a smartphone. The self-assessment test of creating an information product revealed that $55.5 \%$ of practicing teachers have difficulty in creating an electronic educational resource. They lack experience in creating digital educational products. Most 
of the respondents $(77 \%)$ have a lack independent experience in creating an educational video product. The overall indicator of the operational-activity component formation was distributed in following way: $36 \%$ of the respondents showed a high level of this component formation, $38 \%$ of the respondents was at an average level, $26 \%$ of the respondents at showed an insufficient level. As for the formation of the motivational-value component, $89 \%$ of teachers had a high level.

Our research examines the methodological aspects of the content components formation of digital competencies that are directly related to the educational process. The methodological aspects of the formation of digital competencies, which correspond to information and media literacy, are also considered [10].

\section{Discussion}

When analyzing the methodological aspects of the formation of digital competencies in order to prepare students for professional pedagogical actions, it is advisable to single out those methodological disciplines within which specialized practical activities are implemented, which are subject to innovative changes, the essence of which is to obtain new products - namely, digital skills, abilities and knowledge.

In the curriculum of students of life safety and physical education specialties, the discipline "Information and communication technologies and media information literacy" was introduced into the basic part, which forms universal and general professional competencies. As a result of mastering the discipline, a student enrolled in the direction of pedagogical education masters the methods of searching, critical analysis and synthesis of information, methods of developing basic and additional educational programs and their individual components using information and communication technologies. Digital competencies can be formed not only in the process of implementing general education, but also in specialized disciplines. As part of the implementation of the discipline "Ensuring the safety of educational institutions" among students of the specialty Life Safety and Physical Education, it is possible to form knowledge and skills of organizing pedagogical activities in a digital environment from the standpoint of health preservation. The content aspect includes such topics as: attention management in the digital environment; the structure of a practical online lesson with practice in microgroups from the standpoint of organizing a safe and comfortable educational environment; criteria for effectively setting a task for practice in microgroups online; the use of coaching techniques in training, the formation of an environment in online learning that supports the development of intelligent and independent behavior; using an Agile approach to organizing the educational process from the standpoint of creating a safe and comfortable educational.

In our opinion, an important and relevant direction in the system of professional development of pedagogical university students is industrial training, which will ensure the assimilation of theoretical subject materials inseparably with their implementation in practice, will allow the formation of skills and abilities in the implementation of pedagogical professional activities, which will contribute to the practical formation of training future teachers of the life safety basics. At first in the process of educational, then industrial practice, students gain experience in search and systematization. selection and classification of information for the creation of electronic educational resources, to develop interactive evaluation tools for the effectiveness of teaching schoolchildren, the creation of electronic educational resources and video lectures. The research of students' motivational readiness to study in the process of mastering specialized disciplines with the subsequent use of digital technologies in the design of both their own educational routes and the educational environment of students of general educational organizations in the 
course of their professional activities showed that $87 \%$ of respondents are interested in the content of activities in the electronic environment and see this guarantee of their professional development, enhancing their professional growth and their professional qualities.

\section{Conclusion}

The formation of digital competencies of future life safety teachers is a process of purposeful pedagogical influence on the student in order to develop a set of skills, abilities and knowledge, allowing him to effective use of digital technologies to solve professional problems at all levels of education, including the search, creation, use of digital educational resources, the use of digital tools in teaching and learning, in assessing the effectiveness of learning outcomes, the development of the students' educational potential and their digital competence and safe information and environmental activities.

The formation of digital competencies of students, future life safety teachers is possible when implementing specialized disciplines and educational and industrial practices that include in their content the organization of pedagogical activities in a digital environment from the standpoint of health preservation, creating a favorable and comfortable educational environment.

\section{References}

1. A.M. Kondakov, A.A. Kostyleva, Digital education: from school for everyone to school for everyone, RUDN University journal on informatization in education, 16 (4), 295-307 (2019)

2. E.M. Meyers, I. Erickson, R.V. Maly, Digital literacy and informal learning environment: introduction, Education, media and technologies, 38 (4), 355-367 (2013)

3. Structure of ICT competence of teachers, UNESCO Recommendations

4. R.E. Gerasimova, The need for additional vocational education in modern conditions, Scientific and methodological electronic journal "Concept", 32, 268-270 (2017)

5. I.V. Robert, Didactics of the era of digital information technologies, Professional Education. Capital, 3, 16-26 (2019)

6. I.A. Winter, Competence and competence, Studentship. Dialogues about education, 6, 13-14 (2004)

7. E. Stellman, D. Green, Comprehending agile: values, principles, methodologies (2017)

8. S. Sergis, D.G. Sampson, M. Giannakos, Improving students' digital skills: applying an ecosystem-based school analytics approach, Proceedings of the 17th IEEE International Conference on Advanced Learning Technologies, ICALT, 21-25 (2017)

9. A.M. Novikov N73 Pedagogy: a dictionary of the system of basic concepts, IET Publishing Center, 268 (2013)

10. K. Redecker, J. Puni, European Framework for Digital Competence for Teachers: DigCompEdu (2017)

11. E.V. Liksina, The problem of the formation of ICT competence of teachers in the context of the implementation of the standard, Eurasian Union of Scientists (ESU), 10 (55), 32-34 (2018) 
12. N.P. Tabachuk, Information, digital and smart competencies of the individual: transformation of views, Scientific and pedagogical review (Pedagogical Review), 4 (26), 133-141 (2019)

13. N.P. Tabachuk, Information competence of the individual as a subject of activity, Scientific and pedagogical review, 3 (17), 40-44 (2017)

14. A.B. Razumova, N.A. Mukhamedyarova, E.F. Shklyaruk, The value of the teacher's information competence as a condition for supporting the child's development, Yaroslavl Pedagogical Bulletin, 6, 187-191 (2016)

A. Breiter, S. Aufenanger, I. Averbeck, S. Welling, M. Vegelek, Media Integration in Grundschulen, Berlin: prospects (2013)

15. D.A. Saitova, Development of media education using digital media in schools of the Federal Republic of Germany (FRG), Internet Journal "World of Science", 5 (4) (2017)

16. L. Hansen, H. Nissenbaum, Digital Catastrophe, Cybersecurity and the Copenhagen School, Quarterly by international research, 53 (4), 1155-1175 (2009)

17. L.A. Akimova, I.V. Chikeneva, Safe educational environment as an object of pedagogical design, Humanities and Social Sciences, 7 (5), 510-515 (2019)

18. L.A. Akimova, E.E. Lutovina, I.V. Chikeneva, Norms of physical culture and health protection in the education system, Theory and practice of physical culture, 4, 23 (2019)

19. Yu.I. Bogatyreva, Information security of schoolchildren in the educational environment: theory and practice of higher education (Tula, 2013) 